\title{
openheart Coronary heart disease and stroke in the Sami and non-Sami populations in rural Northern and Mid Norway - the SAMINOR Study
}

\author{
Susanna R A Siri (D , , ${ }^{1}$ Bent M Eliassen, ${ }^{2}$ Ann R Broderstad, ${ }^{1,3}$ Marita Melhus, ${ }^{1}$ \\ Vilde L Michalsen, ${ }^{1}$ Bjarne K Jacobsen, ${ }^{1}$ Luke J Burchill, ${ }^{4}$ Tonje Braaten ${ }^{1}$
}

\begin{abstract}
- Additional material is published online only. To view please visit the journal online (http://dx.doi.org/10.1136/ openhrt-2019-001213).
\end{abstract}

To cite: Siri SRA, Eliassen BM Broderstad AR, et al. Coronary heart disease and stroke in the Sami and non-Sami populations in rural Northern and Mid Norway - the SAMINOR Study. Open Heart 2020;7:e001213. doi:10.1136/

openhrt-2019-001213

Received 28 November 2019 Revised 27 February 2020 Accepted 26 March 2020

Check for updates

(c) Author(s) (or their employer(s)) 2020. Re-use permitted under CC BY-NC. No commercial re-use. See rights and permissions. Published by BMJ.

${ }^{1}$ Department of Community Medicine, Centre for Sami Health Research, Faculty of Health Sciences, UiT The Arctic University of Norway, Tromso, Norway

${ }^{2}$ Faculty of Nursing and Health Sciences, Nord University, Bodo, Nordland, Norway

${ }^{3}$ Department of Medicine, University Hospital of North Norway, Harstad, Troms, Norway ${ }^{4}$ Department of Medicine, Royal Melbourne Hospital, The University of Melbourne, Melbourne, Victoria, Australia

Correspondence to Susanna R A Siri; susanna.r. siri@uit.no

\section{ABSTRACT}

Background Previous studies have suggested that Sami have a similar risk of myocardial infarction and a possible higher risk of stroke compared with non-Sami living in the same geographical area.

Design Participants in the SAMINOR 1 Survey (20032004) aged 30 and 36-79 years were followed to the 31 December 2016 for observation of fatal or non-fatal events of acute myocardial infarction (AMI), coronary heart disease (CHD), ischaemic stroke (IS), stroke and a composite endpoint (fatal or non-fatal AMl or stroke).

Aim Compare the risk of AMI, CHD, IS, stroke and the composite endpoint in Sami and non-Sami populations, and identify intermediate factors if ethnic differences in risks are observed.

Methods Cox regression models.

Results The sex-adjusted and age-adjusted risks of AMI (HR for Sami versus non-Sami 0.99, 95\% Cl: 0.83 to 1.17), CHD (HR 1.03, 95\% Cl: 0.93 to 1.15) and of the composite endpoint (HR 1.09, 95\% Cl: 0.95 to 1.24) were similar in Sami and non-Sami populations. Sami ethnicity was, however, associated with increased risk of IS (HR 1.36, $95 \% \mathrm{Cl}: 1.10$ to 1.68 ) and stroke (HR $1.31,95 \% \mathrm{Cl}: 1.08$ to 1.58). Height explained more of the excess risk observed in Sami than conventional risk factors.

Conclusions The risk of IS and stroke were higher in Sami and height was identified as an important intermediate factor as it explained a considerable proportion of the ethnic differences in IS and stroke. The risk of $\mathrm{AMI}, \mathrm{CHD}$ and the composite endpoint was similar in Sami and non-Sami populations.

\section{INTRODUCTION}

Through 2001 to 2014, the incidence of non-fatal acute myocardial infarction (AMI) and fatal coronary heart disease (CHD) declined in Norway in both sexes, ${ }^{1}$ even among people aged 25-44 years. ${ }^{1}$ Between 1994 and 2012, a decline was observed in the incidence of $\mathrm{CHD}^{2}$ and stroke $\mathrm{e}^{3}$ in the largest city in Northern Norway, which is close to the regions included in the present study. The decline in the incidence of CHD and stroke was mainly driven by the improvement of

\section{Key questions}

What is already known about this subject?

- Previous studies have found similar risk of coronary heart disease and a possible higher risk of stroke in Sami compared to non-Sami populations.

What does this study add?

- In the SAMINOR 1 Survey (2003-2004), the Sami population has a higher risk of stroke and ischaemic stroke compared with non-Sami. Differences in height explained more than conventional risk factors.

How might this impact on clinical practice?

- Our findings have predominantly public health relevance. The clinical relevance depend on the interpretation of height and ethnicity as risk predictors of ischemic stroke and stroke.

cardiovascular risk factors ${ }^{3}$; for fatal CHD, fewer out-of-hospital sudden deaths and hospitalisations with severe myocardial infarction (MI) contributed to the decline. ${ }^{2}$

The Sami people live across Norway, Sweden, Finland and on the Kola Peninsula in the Russian Federation. In Norway, the Sami are acknowledged as indigenous people, and the majority live in Northern Norway, together with the Kven people and Norwegian majority population. The Kven people are descendants of Finnish-speaking immigrants who arrived in the 1700 s and 1800s from northern Sweden and Finland. ${ }^{4}$ As with other indigenous people, the Norwegian government imposed harsh assimilation policies on the Sami from 1850 until 1960, ${ }^{5}$ when a revitalisation of Sami culture and languages began, but many had already given up using Sami languages. In the 1970 population census, information on Sami and Kven ethnicities was collected in selected areas of Northern Norway, and it was estimated that around 40000 people in Norway were Sami. ${ }^{6}$ 
Unlike other indigenous populations, ${ }^{7}$ the somatic health in Sami has been shown to be similar to that in the nonSami population in the same geographical areas. ${ }^{8}$

Two studies regarding CHD mortality in Sami, covering roughly the same time period but different geographical areas, show contradicting mortality rates, ${ }^{9}{ }^{10}$ whereas similar incidence of MI was observed in Sami and nonSami in 1973/1974 through 1989 in Finnmark County, in Northern Norway. ${ }^{11}$ With regards to stroke, higher mortality $^{9}$ and possibly higher incidence ${ }^{11} 12$ were observed in Sami compared with their reference populations in the years 1974-1998. Moreover, several studies observed lower average heights in Sami than in non-Sami populations, ${ }^{10} 1314$ and a possible inverse association between height and degree of Sami affiliation. ${ }^{13}$ Moreover, an increase in height has been found to be inversely associated with CHD and stroke ${ }^{15} 16$ which has also been observed in Finnmark, ${ }^{12}$ however, for MI, this was only found in women. ${ }^{11}$

We have previously reported overall similar levels of cardiovascular risk factors in Sami and non-Sami populations in rural Northern Norway. ${ }^{17}{ }^{18}$ However, it is not known whether the incidence of cardiovascular disease (CVD) differs in Sami and non-Sami in this population. Thus, the aim of this study was to compare the risk of fatal or non-fatal AMI, CHD, ischaemic stroke (IS), stroke and a composite endpoint (AMI or stroke) in Sami and non-Sami populations, and identify intermediate factors if ethnic differences in risks are observed.

\section{METHODS}

The SAMINOR 1 Survey (SAMINOR 1) was conducted in 2003-2004 and was the first of three population-based cross-sectional surveys, which together constitute the SAMINOR Study. The SAMINOR 1 was initiated due to limited knowledge about the health of the Sami population, and it was conducted by the Centre for Sami Health Research at UiT the Arctic University of Norway, together with the Norwegian Institute of Public Health. There is no registry of ethnicity in Norway; thus, SAMINOR 1 invited all inhabitants aged 30, 36-78/79 years (birth cohorts 1925-1967 and 1973 in 2003; birth cohorts 19251968 and 1974 in 2004) residing in 24 selected municipalities of Northern and Mid Norway, all of which had a considerable Sami population according to the 1970 census $^{6}$ and local knowledge. SAMINOR 1 included a clinical examination and self-administrated questionnaires, which included questions related to ethnicity. In total, 27987 individuals were invited and 16865 (60.3\%) attended SAMINOR $1 .^{19}$

\section{Clinical examination}

Trained staff conducted the clinical examinations, during which waist circumference was measured at the umbilicus to the nearest centimetre when participants were standing. Height in centimetres and weight in kilograms were measured with an electronic height and weight scale (DS-102, Dongsahn Jenix, Seoul, Korea) to the nearest 0.1 decimal, with the participant standing and wearing no shoes. A digital oscillometric device (DINAMAP-R, Critikon, Tampa, Florida, USA) was used to measure blood pressure three times at 1-minute intervals, and the average of the last two measurements was reported. Those who used antihypertensive medications or had systolic or diastolic blood pressure $\geq 140 / 90 \mathrm{~mm}$ $\mathrm{Hg}$, respectively, were categorised as hypertensive. Nonfasting venous blood samples were taken while participants were resting. The samples were centrifuged within 30 min, separated within 2 hours and sent by overnight post to Ullevål University Hospital in Oslo, Norway, where total cholesterol, high-density lipoprotein (HDL) cholesterol, glucose and triglycerides were measured with an enzymatic method (Hitachi 917 autoanalyser, Roche Diagnostics, Switzerland).

\section{Self-administered questionnaires}

There is no registry on ethnicity in Norway and health surveys rely on self-reported ethnic information. There is no consensus on how ethnicity should be operationalised in health research except that it is recommended that several markers of ethnicity are applied, as ethnicity is a multifaceted concept. ${ }^{20-22}$ The following 11 questions provided information about ethnicity: (1) What language do/did you, (2) your mother, (3) your father, (4-7) your grandparents (all four) speak at home? (8) What is your, (9) your mother's, (10) your father's ethnic background? (11) What do you consider yourself to be? To each of the questions, one or more of the following alternatives could be ticked: Sami, Kven, Norwegian and other (specify). Participants who (1) considered themselves as Sami or ticked 'Sami' as their own ethnic background, and (2) either spoke the Sami language themselves, or had at least one parent or grandparent who used it at home, were categorised as Sami. All others were categorised as non-Sami. Sensitivity analyses were performed using an alternative ethnic categorisation: (1) high Sami affiliation, that is, reported Sami to all 11 questions $(n=1385)$, (2) some Sami affiliation, that is, reported Sami in 1-10 questions $(n=3168)$, and (3) no Sami affiliation, that is, did not answer Sami in any of the questions $(\mathrm{n}=9234)$.

A family history of premature MI was considered present if first-degree relatives (parents, siblings or children) had MI before the age of 60 years. Disease status was obtained by asking if participants had MI, stroke/brain haemorrhage, angina pectoris and diabetes mellitus, and, if so, then age at which the condition first occurred. Participants with self-reported diabetes mellitus or glucose $\geq 11.1 \mathrm{mmol} / \mathrm{L}$ were categorised as having diabetes. Participants reported whether they were current, previous, or never users of antihypertensive or lipid-lowering medications. Previous and never users were merged with those who failed to reply to the question (missing values for antihypertension medication, $\mathrm{n}=142$ ) and categorised as non-users.

Information on education and behaviour were collected through the questions: How many years of 
education have you completed? Are you currently, or were you previously a daily smoker? (Response alternatives: currently, previously, or never - previous smokers and neversmokers were merged into non-smokers); what was your alcohol consumption in the last year? (Response alternatives: never consumed alcohol, not during the last year, a few times during the last year, one time per month, two to three times per month, one time per week, two to three times per week or four to seven times per week). We created a three-level category, consisting of (1) never consumers together with those who did not consume in the last year, (2) those who consumed less than weekly and (3) those who consumed at least weekly. Leisure-time physical activity in the last year was measured using the 'Saltin-Grimby' four-level scale. ${ }^{23}$ Being sedentary during leisure time was defined as: reading, watching television or other sedentary activity, whereas the remaining three alternatives, all of which compromised some physical activity, were merged to describe those who were physically active during leisure time. The estimated 10-year risk of fatal or non-fatal AMI or stroke was computed using the NORRISK 2 score. ${ }^{24}$

\section{Data from national registries}

Linkage to the following national registries was done using each participant's unique, 11-digit national identity number: the Norwegian Cause of Death Registry provided dates and underlying causes of death for 2003-2016; the Cardiovascular Disease Project ${ }^{25}$ provided information on all hospitalisations with CVD as the main or secondary discharge code for 1993-2009; the Norwegian Patient Registry provided records from all hospitalisations with discharge codes including CVD as the main or secondary diagnoses for 2010-2016; and Statistics Norway provided information on emigrations.

The five endpoints included the following codes from the International Classification of Disease, 10th Revision: (1) AMI: I21-22 as the hospital discharge code, or I20-25 as the underlying cause of death code. (2) CHD: I20-25 as the hospital discharge code or the underlying cause of death code. (3) IS: I63 as the hospital discharge code or the underlying cause of death code. (4) Stroke: I60-61 and I63-64 (except I63.6) as hospital discharge code or underlying cause of death code. (5) Composite endpoint, representing the NORRISK 2 endpoint: I21-22 and I60-61, I63-64 (except I63.6) as the hospital discharge code, or I20-25 and I60-61, I63-64 (except I63.6) as the underlying cause of death code. ${ }^{24}$

\section{Study sample}

Among the 16865 individuals who attended the SAMINOR 1 , we excluded 87 who did not consent to have their data linked to registries; 1027 who did not complete one or both of the questionnaires; 35 who did not attend the clinical examination; and 51 who had missing information on ethnicity. Furthermore, we excluded 1580 with self-reported angina pectoris, MI and stroke (the two latter have moderate to high agreement in this population when validated against hospital discharge diagnoses) ${ }^{26}$ and 151 with CHD or stroke as main or secondary hospital discharge code prior to participation in SAMINOR 1. Due to missing values in conventional risk factors $(n=128)$ and height $(\mathrm{n}=19)$, the final sample consisted of 13787 individuals $(49.3 \%$ of the invited sample).

\section{Statistical analyses}

Sample characteristics are given for each stratum of sex and ethnicity, as mean values with SD or as proportions with numbers. The instantaneous hazards in Sami and non-Sami were compared by Cox regression models using age as the time axis, ${ }^{2728}$ whereby each model was adjusted for age. In model 1, the risk estimates for ethnicity were adjusted for age and sex. We then adjusted for potential intermediate factors: first for height per $5 \mathrm{~cm}$ (model 2), and then for conventional risk factors included in the risk prediction model NORRISK 2 score, ${ }^{24}$ systolic blood pressure, total cholesterol, HDL cholesterol, current smoking, use of antihypertensive medication and whether one or two family members had a history of premature MI (model 3). Due to the potential for non-linearity in risk for the continuous variables ${ }^{29}$ we re-ran model 3 (and model 4 in sensitivity analyses) while allowing for multiple fractional polynomials using the 'mfp' function in STATA, an extension of the conventional polynomial model allowing for flexible parametrisation of a continuous predictor. The results from these models showed that only systolic blood pressure could be transformed using different power and degree of freedom, but only in models with AMI, CHD and the composite endpoint. Importantly, the $\beta$-coefficients for ethnicity did not differ in the linear models compared with the models that included the transformed variable, thus, linear models were chosen for all endpoints.

For all endpoints, we assessed the presence of interaction by including product terms with ethnicity and sex, respectively, in separate models for each covariate included in models 2 and 3. In the presence of interaction (AMI: sex and antihypertensive medication; stroke and composite endpoint: sex and height), we included a product term in the models. The proportional hazard assumption was assessed by checking if the Schoenfeld residuals were independent of attained age at a 5\% significance level, and if necessary, by visual inspection of log-minus-log graphs. If a covariate violated the proportional hazards assumption, then it was included as a time-varying covariate.

Participants in the study were followed from the date of enrolment in SAMINOR 1 until the date of the first nonfatal or fatal event of the specific CVD endpoint, death from other causes, emigration or end of follow-up (31 December 2016), whichever occurred first. A two-sided p-value $<0.05$ was considered statistically significant. All statistical analyses were performed using STATA V.15.1. Figure 1 was made using the open-source software $\mathrm{R}$ V.3.6.0 (Foundation for Statistical Computing, Vienna, Austria).

We conducted the following sensitivity analyses: 
1. We additionally adjusted for waist circumference, diabetes, physical activity in leisure time, alcohol consumption and years of education (model 4), but in a smaller sample due to missing values in these covariates ( $\mathrm{n}=12078$, results not shown).

2. We performed Fine \& Gray competing risk survival analyses with deaths from other causes as competing events, as previous studies have found somewhat higher rates of total mortality and violent death in Sami than non-Sami populations. ${ }^{9}$

3. Models 1-3 were repeated using the alternative ethnic categorisations.

4. To account for potential geographical heterogeneity, we adjusted for regions in all three models, using region 1 (see table 1 for the definition of regions) as reference.

\section{RESULTS}

The final sample constituted of $21.7 \%$ Sami and more women $(53.7 \%)$ than men. The age distribution was similar in Sami and non-Sami, both in men and women. The crude mean values for height showed that Sami men and women in this sample were 6.0 and $5.7 \mathrm{~cm}$ shorter than non-Sami men and women, respectively (both $\mathrm{p}<0.001$, age-adjusted linear regression, results not shown). A higher proportion of Sami participants reported a family history of premature MI, and a higher proportion reported abstaining from alcohol or a seldom alcohol consumption. A higher proportion of Sami than non-Sami men reported being current smokers, and Sami men had a somewhat higher mean estimated 10-year risk of AMI or stroke. In this sample, Sami women had a somewhat lower mean systolic blood pressure than non-Sami women, whereas a higher proportion of non-Sami was categorised as hypertensive. Additionally, a lower proportion of Sami women reported being physically active in their leisure time (table 1).

The median follow-up time and age for the composite endpoints were 13.0 and 65.2 years, respectively. The number of fatal and non-fatal events by investigated endpoints were as follows: AMI, 102 and 672; CHD, 89 and 1882; IS, 9 and 423; stroke, 36 and 525; and the composite endpoint, 129 and 1130, respectively. Among censored cases, there were 101 participants who emigrated during follow-up.

For all endpoints considered, we found no statistically significant interactions between ethnicity and height, between ethnicity and sex, or between ethnicity and year of birth. Although the estimates for men and women were not different in Sami and non-Sami, we included the sex-specific and ethnicity specific incidence rates per 1000 person-years in a supplementary table (online supplementary table 1).

The number of cases, person-years and incidence rates (per 1000) by ethnic group are listed in figure 1. For each

\section{Crude incidence rates and adjusted hazard ratios for Sami vs. non-Sami}

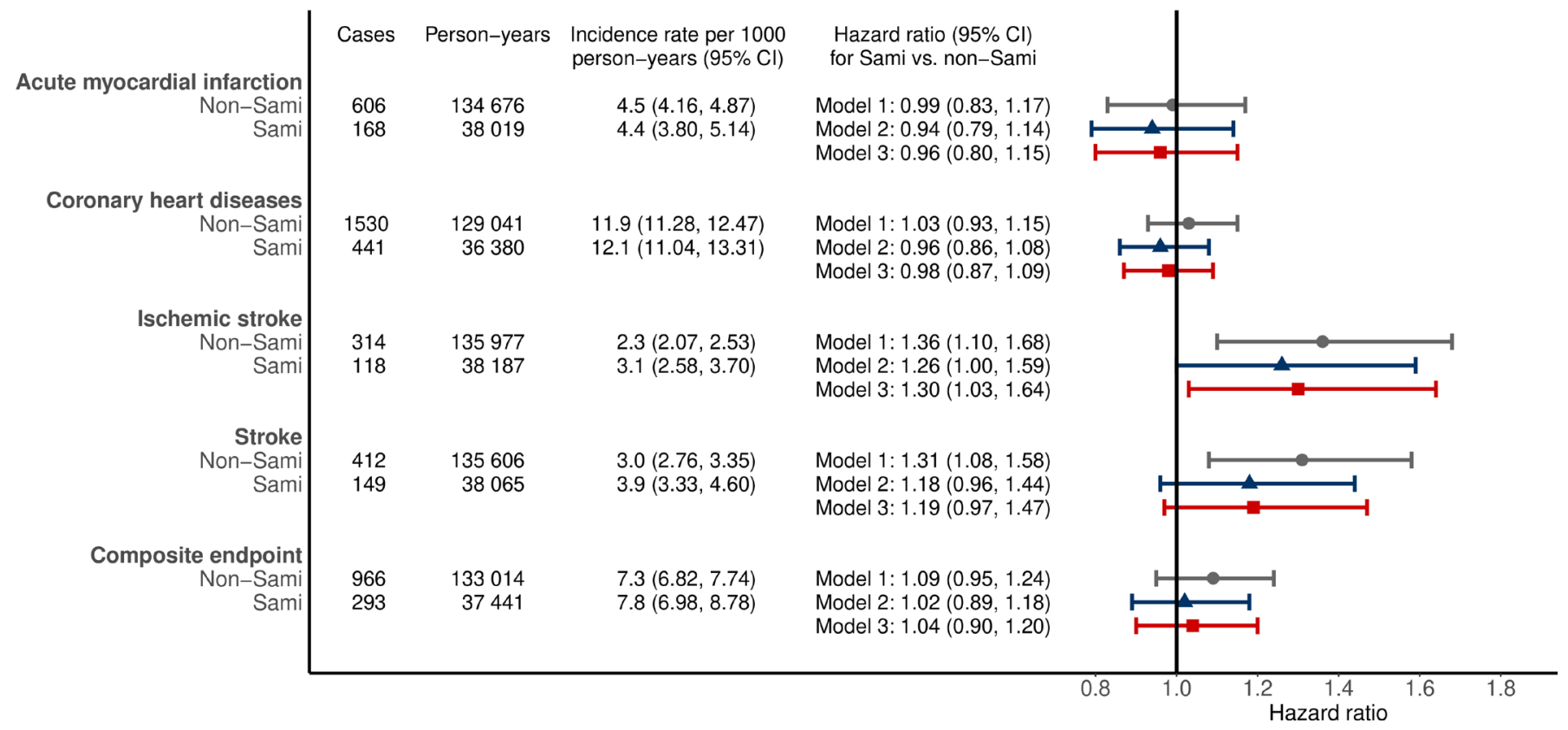

Figure 1 Number of cardiovascular events, person-years and incidence rates in Sami and non-Sami people who participated in the SAMINOR 1 Survey in 2003/2004 and were followed to the end of 2016. The forest plot gives the adjusted risk (HR with $95 \% \mathrm{Cl})$ in Sami $(n=2990)$ for different cardiovascular endpoints using non-Sami $(n=10797)$ as reference and age as the time axis in Cox regressions models, adjusting for the following covariates: model 1, sex; model 2, sex and height; model 3 , sex, height, systolic blood pressure, total cholesterol, high-density lipoprotein cholesterol, current smoking (yes/no), use of antihypertensive medication (yes/no) and if one or two family members had a history of premature myocardial infarction (yes/ no). 
Table 1 Crude sample characteristics for the SAMINOR 1 population $(n=13787)$ given as means and SD or proportions and numbers

\begin{tabular}{|c|c|c|c|c|}
\hline & \multicolumn{2}{|l|}{ Men } & \multicolumn{2}{|l|}{ Women } \\
\hline & $\begin{array}{l}\text { Non-Sami } \\
(\mathrm{n}=4971)\end{array}$ & $\begin{array}{l}\text { Sami } \\
(n=1408)\end{array}$ & $\begin{array}{l}\text { Non-Sami } \\
(\mathrm{n}=5826)\end{array}$ & $\begin{array}{l}\text { Sami } \\
(n=1582)\end{array}$ \\
\hline Age (years) & $52.8(10.8)$ & $52.9(10.8)$ & $52.8(11.3)$ & $52.1(11.2)$ \\
\hline Height $(\mathrm{cm})$ & $175.6(6.9)$ & $169.6(6.4)$ & $162.5(6.4)$ & $156.8(6.0)$ \\
\hline Systolic blood pressure $(\mathrm{mm} \mathrm{Hg})$ & $134.0(18.0)$ & $133.3(19.0)$ & $129.2(20.9)$ & $127.2(20.9)$ \\
\hline Diastolic blood pressure $(\mathrm{mm} \mathrm{Hg})$ & $78.3(10.0)$ & $77.9(9.8)$ & $72.7(10.2)$ & $72.1(10.1)$ \\
\hline Total cholesterol (mmol/L) & $6.02(1.1)$ & $6.04(1.1)$ & $5.99(1.2)$ & $6.01(1.1)$ \\
\hline HDL cholesterol (mmol/L) & $1.26(0.33)$ & $1.27(0.35)$ & $1.49(0.38)$ & $1.44(0.37)$ \\
\hline \multicolumn{5}{|l|}{ Smoking } \\
\hline Current smoker & $31.5(1566)$ & 34.7 (488) & $32.3(1882)$ & $33.0(522)$ \\
\hline Previous smoker & $37.7(1876)$ & $37.0(522)$ & $30.5(1777)$ & $28.1(445)$ \\
\hline Never smoker & $30.8(1529)$ & $28.3(398)$ & $37.2(2167)$ & $38.9(615)$ \\
\hline \multicolumn{5}{|l|}{ Family history of premature $\mathrm{Ml}^{*}$} \\
\hline One family member & $19.4(960)$ & $20.0(281)$ & 20.1 (1171) & $21.4(337)$ \\
\hline Two family members & $3.0(147)$ & $4.5(63)$ & $4.2(242)$ & $5.8(91)$ \\
\hline Users of antihypertensive medication† & $13.7(681)$ & $13.5(190)$ & $16.6(969)$ & $16.1(254)$ \\
\hline Estimated 10 -year risk of fatal or non-fatal AMI or strokeł‡ & $8.82(7.9)$ & $9.13(8.1)$ & $4.76(6.0)$ & $5.73(4.4)$ \\
\hline Triglycerides (mmol/L)† & $1.87(1.31)$ & $1.87(1.16)$ & $1.50(0.86)$ & $1.55(0.88)$ \\
\hline Hypertensive & $39.5(1963)$ & $38.6(543)$ & $35.7(2078)$ & $32.1(508)$ \\
\hline Users of lipid-lowering drugs† & $7.1(354)$ & $8.6(121)$ & $8.7(506)$ & $8.7(137)$ \\
\hline Waist circumference $(\mathrm{cm}) \dagger$ & $94.3(10.3)$ & $92.3(10.9)$ & $85.1(11.9)$ & $85.3(11.9)$ \\
\hline Diabetes mellitus & $3.4(167)$ & $4.1(58)$ & $3.5(202)$ & $3.4(53)$ \\
\hline Physically active in leisure time $\dagger$ & $76.7(3565)$ & $75.7(977)$ & $78.4(4134)$ & $72.1(1037)$ \\
\hline \multicolumn{5}{|l|}{ Alcohol consumption† } \\
\hline Never/not last year & $8.5(416)$ & $12.9(177)$ & $17.1(966)$ & $28.6(436)$ \\
\hline Less than weekly & $58.2(2843)$ & $61.2(838)$ & $60.9(3443)$ & $58.3(890)$ \\
\hline Weekly or more often & $33.3(1626)$ & $25.9(354)$ & $22.0(1241)$ & $13.1(199)$ \\
\hline Years of education $†$ & $11.5(3.7)$ & $11.0(4.0)$ & $11.7(3.8)$ & $11.6(4.5)$ \\
\hline $\begin{array}{l}\text { Region 1: Alta, Loppa, Kvalsund, Lebesby, Lyngen, Storfjord, Kåfjord, } \\
\text { Kvænangen§ }\end{array}$ & $62.7(3117)$ & $31.9(449)$ & $62.6(3646)$ & $28.2(446)$ \\
\hline Region 2: Kautokeino. Karasjok§ & $1.3(66)$ & $28.7(404)$ & $1.5(89)$ & $33.1(524)$ \\
\hline Region 3: Tana, Nesseby, Porsanger§ & $10.6(527)$ & $28.1(396)$ & $11.0(639)$ & $29.1(460)$ \\
\hline $\begin{array}{l}\text { Region 4: Narvik, Evenes, Tysfjord, Skånland, Lavangen, Røros, Snåsa, } \\
\text { Røyrvik, Namsskogan, Grane, Hattfjelldal§ }\end{array}$ & $25.4(1261)$ & $11.3(159)$ & $24.9(1452)$ & $9.6(152)$ \\
\hline
\end{tabular}

*Parents, siblings or children with MI before the age of 60 years.

†Missing values: users of antihypertensive medication, $n=142$; estimated 10-year risk in men, $n=13$; triglycerides, $n=12$; waist circumference, $n=47$; education, $n=770$; users of lipid lowering drugs, $n=300$; physical activity, $n=1185$; alcohol consumption, $n=358$. ¥Estimated 10-year risk is measured with the NORRISK 2 risk score including sex, age, systolic blood pressure, total and HDL cholesterol, smoking (yes/no), use of antihypertensive medication (yes/no) and if one or two family members had a history of premature $\mathrm{Ml}$ (yes/no).

§lncluded the listed municipalities.

HDL, high-density lipoprotein; MI, myocardial infarction.

endpoint, the HRs and 95\% CIs in Sami versus non-Sami are visualised for model 1 to 3 with a forest plot (figure 1). We found no ethnic differences in the age-adjusted and sexadjusted (model 1) or the multivariable-adjusted (model 2-3) risk of AMI, CHD or in the composite endpoint. Regarding IS and stroke, Sami had higher age-adjusted and sex-adjusted risks than non-Sami, with HR of 1.36 (95\%
CI: 1.10 to 1.68 ) and 1.31 (95\% CI: 1.08 to 1.58 ), respectively. Adjustment for height attenuated the relationships between ethnicity and IS, and ethnicity and stroke to HR 1.26 (95\% CI: 1.00 to 1.59 ) and 1.18 (95\% CI: 0.96 to 1.44), respectively. Further adjustment for conventional risk factors (model 3) increased the risk of IS and stroke 
somewhat (to HR 1.30 (95\% CI: 1.03 to 1.64 ) and 1.19 (95\% CI: 0.97 to 1.47 ), respectively) (figure 1).

A significant interaction between sex and height was present in the models for stroke and the composite endpoint. Sex-stratified analyses revealed that height was inversely associated with stroke (model 2, HR per $5 \mathrm{~cm}$ increase: $0.84,95 \% \mathrm{Cl}: 0.76$ to 0.94$)$ and the composite endpoint (model 2, HR per $5 \mathrm{~cm}$ increase: $0.89,95 \% \mathrm{Cl}$ : 0.82 to 0.96 ), only in women (online supplementary table 2).

The sensitivity analyses rendered results that were consistent with those reported above.

\section{DISCUSSION}

In this population-based study from Northern and Mid Norway with a median of 13 years of follow-up, we found that Sami had a higher risk of IS and stroke than nonSami, and a considerable part was explained by differences in height. No ethnic differences were observed with regards to AMI, CHD and the composite endpoint consisting of fatal or non-fatal AMI or stroke.

Our findings of higher incidence of IS and stroke in Sami compared with non-Sami is supported by studies in Norway and Sweden that indicate a higher incidence ${ }^{111230}$ and higher mortality of stroke in Sami. ${ }^{9}$ However, similar mortality of stroke was found between Sami and nonSami in Sweden and Northern Finland..$^{30} 31$

We observed a similar risk of CHD and AMI in Sami and non-Sami, which is consistent with the results regarding MI from a study based on data from 1974/1975 to 1989 that included the population in the Finnmark County. ${ }^{11}$ A different study, covering the same population and time period, found lower total mortality, CVD mortality and CHD mortality in Sami men, whereas no ethnic difference was observed between Sami and non-Sami women. ${ }^{10}$ Another study followed Sami identified through a population census in Northern Norway from 1970 to 1998 and found that Sami had higher total mortality, CVD mortality and CHD mortality than their benchmark population. ${ }^{9}$ However, as we included both fatal and non-fatal events, direct comparisons of mortality rates are challenging. In Finland, lower and similar mortalities have been observed in Sami, ${ }^{31} 32$ whereas in Sweden, no overall differences in incidence and mortality are observed when compared with reference non-Sami populations. ${ }^{30}$ Being a member of a Sami reindeer herding household may, however, be protective. $^{9} 30$

It seems likely that Sami people have a higher risk of IS and stroke than non-Sami, and similar risk of AMI and CHD, as this corresponds well with previous studies. We note that our age-adjusted and sex-adjusted effect estimates (model 1) are important from a public health perspective, as they reflect the actual distribution of risk in these populations. In our study, we were able to provide some explanation for the differences in risks, as the results for IS and stroke were attenuated, becoming only borderline significant after adjustment for height and conventional risk factors. However, the effect estimates for IS and stroke remained elevated after adjustments (models 2 and 3), which suggests that there might be other intermediate factors that we have not accounted for.

When adjusting for height, we most likely adjusted for factors that are related to health, nutrition and socioeconomic conditions, within and across generations, ${ }^{33}{ }^{34}$ and genetic factors ${ }^{15}{ }^{35}$ which all influence the body height of an individual. Adjusting for baseline values of conventional risk factors (model 3) had only a small impact on the associations between ethnicity and IS, and ethnicity and stroke. This was as expected, given the similar baseline levels of conventional risk factors found in Sami and non-Sami at two time points. ${ }^{17} 18$ The Emerging Risk Factors Collaboration included over 1 million people and found that after adjusting for height, further adjustments for long-term exposure to cardiovascular risk factors had little impact on the mortality-specific risk estimations. ${ }^{16}$ They suggested that adult height is influenced by factors that also influence cardiovascular risk through the shared biological process between genes that determine adult height and atherosclerosis, ${ }^{16}$ which has been considered by others. ${ }^{36}$ For the risk of CHD, an increase in genetically determined height $(6.5 \mathrm{~cm})$ has been associated with the lower body mass index, ${ }^{37}$ lower cholesterol ${ }^{36} 37$ and better lung function, ${ }^{37} 38$ whereas for stroke, the associations were less certain. ${ }^{37}$ Some argue that height has a direct effect as short people have proportionally smaller coronary arteries that are occluded earlier than in tall persons by a similar burden of plaque. ${ }^{39}$ Shorter people are found to have higher blood pressure ${ }^{40}$ and increased heart rate due to a smaller arterial tree ${ }^{41}$ than in taller people. The precise mechanism linking short stature with increased risk of CHD and stroke remains uncertain.

We found no ethnic differences in the risk of AMI and CHD. CVD is multifactorial in origin, and comparison groups may differ with regards to unmeasured risk or protective factors. Poor socioeconomic circumstances during childhood are found to have a stronger impact on stroke mortality than CHD mortality, ${ }^{42}$ which suggests some differences in the aetiology of stroke and CHD.

Education and healthcare are publicly financed in Norway, and this has been suggested as the underlying reason for the rather similar health observed previously in Sami and their majority population, as opposed to the situation in other indigenous populations. ${ }^{43}$ Adjusting for baseline education and lifestyle factors (model 4 in sensitivity analyses) had a small impact in our study, and expenditures to secondary healthcare services are found to be similar in geographical areas that represent Sami and non-Sami populations. ${ }^{44}$ Hence, differences in healthcare utilisation and education are most likely not an issue in this population.

All inhabitants, within the selected region and birth cohorts, were invited to the SAMINOR 1, regardless of ethnicity, which should help control some environmental confounding factors that can distort comparison between 
ethnic groups. However, ethnicity itself is rarely the causal factor for diseases, but a risk marker, ${ }^{20}$ representing certain 'exposures' that is determined by group membership. The height difference explained more of the risk of IS and stroke observed in Sami than conventional risk factors, which is interesting but challenging to interpret, as there are complex relationships between height, genetics, ethnicity and environmental factors across generations. ${ }^{345}$ Moreover, we cannot rule out that the excess risk in Sami might be due to residual confounding.

Psychosocial stress has been found to be an important risk factor for stroke, ${ }^{46}$ and the Sami people have been exposed to marginalisation ${ }^{47}$ and ethnic discrimination. $^{48}$ If marginalisation and discrimination cause chronic psychosocial stress, they may lead to a higher risk of IS and stroke in Sami, as was previously suggested by Eliassen et al, who reported that marginalised Sami were more likely to report lifetime CVD. ${ }^{47}$ Thus, further studies that clarify how height and possibly other intermediate factors lead to a higher risk of IS and stroke in Sami are warranted.

\section{Strengths and limitations}

The use of 11-digit national identity numbers to obtain complete follow-up to high-quality registries, ${ }^{25} 49$ and the possibility to remove prevalent cases at baseline represents the strengths of this study. A limitation is that we have only adjusted for baseline values and cannot account for changes in risk factors or in the use of medication.

Potential misclassification of ethnicity is likely to be nondifferential and would have led us to underestimate the associations. With regards to the reliability of ethnicity, Sami ethnicity was found to be stable when comparing information in the 1970 census, that is, language use in three generations and self-reported ethnicity, with corresponding information in SAMINOR $1 .{ }^{50}$ However, we do not know if participation differed by ethnicity as there are no national registries that include this information. Moreover, participants in health surveys tend to be healthier than the underlying population, ${ }^{51}$ which can lead to lower incidence rates.

In conclusion, over 13 years of follow-up, Sami in Northern and Mid Norway showed a higher risk of IS and stroke than non-Sami, and height was identified as an important intermediate factor, as it explained more of the excess risk observed in Sami than conventional risk factors did. Sami and non-Sami participants had similar risk of AMI, CHD and the composite endpoint (AMI or stroke).

Acknowledgements The authors are grateful to the participants of SAMINOR 1 and to those who carried out the survey. The publication charges for this article have been funded by a grant from the publication fund of UiT The Arctic University of Norway.

Contributors TB and BME: conceived the study. MM: linked the different data sources and prepared the research dataset for STATA. SRAS: performed the analyses, wrote the manuscript and made the tables. TB, BKJ and VLM: assisted with statistical analyses and the interpretations of the statistics. VLM: made the figure. All authors critically revised the manuscript, tables and figures, and contributed to drawing the final conclusions.
Funding The first authors PhD was funded by the Centre for Sami Health Research at UiT The Arctic University of Norway. SAMINOR 1 was financed by the Norwegian Ministry of Health and Care Services.

Competing interests None declared.

Patient consent for publication Not required.

Ethics approval The present study (2015/2204-11) is approved by the Regional Committee for Medical and Health Research Ethics for region North (REC North) and by the SAMINOR Project Board. We included those who gave written informed consent to have their data linked to registries, and the data were deidentified before they were available for analyses. The SAMINOR is part of the SAMINOR Study that is approved by The Norwegian Data Inspectorate and the REC North.

Provenance and peer review Not commissioned; externally peer reviewed.

Data availability statement In this study, we have used de-identified participant data which is not available for the public, as it is restricted by licence. Data might, however, be available if a written request is sent to and accepted by the SAMINOR Project Board (www.saminor.no) and by the Regional Committee for Medical and Health Research Ethics for region North.

Open access This is an open access article distributed in accordance with the Creative Commons Attribution Non Commercial (CC BY-NC 4.0) license, which permits others to distribute, remix, adapt, build upon this work non-commercially, and license their derivative works on different terms, provided the original work is properly cited, appropriate credit is given, any changes made indicated, and the use is non-commercial. See: http://creativecommons.org/licenses/by-nc/4.0/.

Correction notice This paper has been updated since first published to update the Key Questions box.

ORCID iD

Susanna R A Siri http://orcid.org/0000-0003-3231-8139

\section{REFERENCES}

1 Sulo G, Igland J, Vollset SE, et al. Trends in incident acute myocardial infarction in Norway: an updated analysis to 2014 using national data from the CVDNOR project. Eur J Prev Cardiol 2018;25:1031-9.

2 Mannsverk J, Wilsgaard T, Mathiesen EB, et al. Trends in modifiable risk factors are associated with declining incidence of hospitalized and nonhospitalized acute coronary heart disease in a population. Circulation 2016;133:74-81.

3 Vangen-Lønne AM, Wilsgaard T, Johnsen SH, et al. Declining incidence of ischemic stroke: what is the impact of changing risk factors? the Troms $\varnothing$ Study 1995 to 2012. Stroke 2017;48:544-50.

4 Niemi E. The Finns in Northern Scandinavia and minority policy. In: Tägil S, ed. Ethnicity and nation building in the Nordic world. London: Hurst, 1995: 145-78.

5 Minde $\mathrm{H}$. Assimilation of the Sami - Implementation and Consequences. Acta Borealia 2003;20:121-46.

6 Aubert V. Den samiske befolkning i Nord-Norge [The Sami population in Northern Norway], 1978. Available: https://www.ssb.no/a/histstat/ art/art_107.pdf [Accessed Mar 2019].

7 Anderson I, Robson B, Connolly M, et al. Indigenous and tribal peoples' health (The Lancet-Lowitja Institute Global Collaboration): a population study. Lancet 2016;388:131-57.

8 Storm Mienna C, Axelsson P. Somatic health in the Indigenous Sami population - a systematic review. Int J Circumpolar Health 2019;78:1638195.

9 Tynes T, Haldorsen T. Mortality in the Sami population of North Norway, 1970-98. Scand J Public Health 2007;35:306-12.

10 Tverdal A. Cohort study of ethnic group and cardiovascular and total mortality over 15 years. J Clin Epidemiol 1997;50:719-23.

11 Njølstad I, Arnesen E, Lund-Larsen PG. Cardiovascular diseases and diabetes mellitus in different ethnic groups: the Finnmark study. Epidemiology 1998;9:550-6.

12 Njølstad I, Arnesen E, Lund-Larsen PG. Body height, cardiovascular risk factors, and risk of stroke in middle-aged men and women. A 14-year follow-up of the Finnmark study. Circulation 1996;94:2877-82.

13 Nystad T, Melhus M, Brustad M, et al. Ethnic differences in the prevalence of general and central obesity among the Sami and Norwegian populations: the SAMINOR study. Scand J Public Health 2010;38:17-24. 
14 Laitinen J, Näyhä S, Sikkilä K, et al. Diet and cardiovascular risk factors among Lapp and Finnish reindeer herders. Nutr Res 1996;16:1083-93.

15 Lai FY, Nath M, Hamby SE, et al. Adult height and risk of 50 diseases: a combined epidemiological and genetic analysis. BMC Med 2018;16:187.

16 Emerging Risk Factors Collaboration. Adult height and the risk of cause-specific death and vascular morbidity in 1 million people: individual participant meta-analysis. Int J Epidemiol 2012;41:1419-33.

17 Michalsen VL, Kvaløy K, Svartberg J, et al. Change in prevalence and severity of metabolic syndrome in the Sami and non-Sami population in rural Northern Norway using a repeated cross-sectional population-based study design: the SAMINOR Study. BMJ Open 2019;9:e027791.

18 Siri SRA, Eliassen BM, Jacobsen BK, et al. Changes in conventional cardiovascular risk factors and the estimated 10-year risk of acute myocardial infarction or cerebral stroke in Sami and non-Sami populations in two population-based cross-sectional surveys: the SAMINOR Study. BMJ Open 2019;9:e028939.

19 Lund E, Melhus M, Hansen KL, et al. Population based study of health and living conditions in areas with both Sámi and Norwegian populations--the SAMINOR study. Int J Circumpolar Health 2007;66:113-28.

20 Kaplan JB, Bennett T. Use of race and ethnicity in biomedical publication. JAMA 2003;289:2709-16.

21 Connelly R, Gayle V, Lambert PS. Ethnicity and ethnic group measures in social survey research. Method Innov 2016;9:205979911664288-10.

22 Bhopal R. Migration, ethnicity, race and health in multicultural societies. Second ed. Oxford: Oxford University Press, 2014.

23 Grimby G, Börjesson M, Jonsdottir IH, et al. The "Saltin-Grimby Physical Activity Level Scale" and its application to health research. Scand J Med Sci Sports 2015;25 Suppl 4:119-25.

24 Selmer R, Igland J, Ariansen I, et al. NORRISK 2: a Norwegian risk model for acute cerebral stroke and myocardial infarction. Eur J Prev Cardiol 2017;24:773-82.

25 Igland J, Tell G, Ebbing M, et al. The CVDNOR project: cardiovascular disease in Norway 1994-2009. description of data and data quality, 2013. Available: https://cvdnor.w.uib.no/files/ 2013/08/CVDNOR-Data-and-Quality-Report1.pdf [Accessed Jun 2019].

26 Eliassen B-M, Melhus M, Tell GS, et al. Validity of self-reported myocardial infarction and stroke in regions with Sami and Norwegian populations: the SAMINOR 1 Survey and the CVDNOR project. BMJ Open 2016;6:e012717.

27 Thiébaut ACM, Bénichou J. Choice of time-scale in Cox's model analysis of epidemiologic cohort data: a simulation study. Stat Med 2004;23:3803-20.

28 Korn EL, Graubard BI, Midthune D. Time-to-event analysis of longitudinal follow-up of a survey: choice of the time-scale. Am J Epidemiol 1997;145:72-80.

29 Groenwold $\mathrm{RHH}$, Klungel OH, Altman DG, et al. Adjustment for continuous confounders: an example of how to prevent residual confounding. CMAJ 2013;185:401-6.

30 Sjölander P, Hassler S, Janlert U. Stroke and acute myocardial infarction in the Swedish Sami population: incidence and mortality in relation to income and level of education. Scand J Public Health 2008;36:84-91.

31 Soininen L, Pukkola E. Mortality of the Sami in northern Finland 1979-2005. Int J Circumpolar Health 2008;67:45-57.
32 Näyhä S. Low mortality from ischaemic heart disease in the Sámi district of Finland. Soc Sci Med 1997;44:123-31.

33 Hatton TJ. How have Europeans grown so tall? Oxf Econ Pap 2014:66:349-72.

34 Perkins JM, Subramanian SV, Davey Smith G, et al. Adult height, nutrition, and population health. Nutr Rev 2016;74:149-65.

35 Jelenkovic A, Sund R, Hur Y-M, et al. Genetic and environmental influences on height from infancy to early adulthood: an individualbased pooled analysis of 45 twin cohorts. Sci Rep 2016:6:28496.

36 Nelson CP, Hamby SE, Saleheen D, et al. Genetically determined height and coronary artery disease. $N$ Engl J Med 2015;372:1608-18.

37 Nüesch E, Dale C, Palmer TM, et al. Adult height, coronary heart disease and stroke: a multi-locus Mendelian randomization metaanalysis. Int J Epidemiol 2016;45:1927-37.

38 Marouli E, Del Greco MF, Astley CM, et al. Mendelian randomisation analyses find pulmonary factors mediate the effect of height on coronary artery disease. Commun Biol 2019;2:119.

39 O'Connor NJ, Morton JR, Birkmeyer JD, et al. Effect of coronary artery diameter in patients undergoing coronary bypass surgery. Circulation 1996;93:652-5.

40 Korhonen PE, Kautiainen H, Eriksson JG. The shorter the person, the higher the blood pressure: a birth cohort study. J Hypertens 2017;35:1170-7

41 Smulyan H, Marchais SJ, Pannier B, et al. Influence of body height on pulsatile arterial hemodynamic data. J Am Coll Cardiol 1998;31:1103-9.

42 Galobardes B, Lynch JW, Davey Smith G. Childhood socioeconomic circumstances and cause-specific mortality in adulthood: systematic review and interpretation. Epidemiol Rev 2004;26:7-21.

43 Johansen K, Møllersen S, Aslaksen J, et al. Sami statistics speak, numbers and commentary, 2018. Available: http://samilogutmuitalit. no/sites/default/files/publications/samiske tall 10 engelsk - web. pdf [Accessed August 2019].

44 Gaski M, Melhus M, Deraas T, et al. Use of health care in the main area of Sami habitation in Norway - catching up with national expenditure rates. Rural Remote Health 2011;11:1655.

45 Zhou W, Li Y, Liu X, et al. Sex-Specific relationship between adult height and the risk of stroke: a dose-response meta-analysis of prospective studies. J Clin Hypertens 2019;21:262-70.

46 O'Donnell MJ, Chin SL, Rangarajan S, et al. Global and regional effects of potentially modifiable risk factors associated with acute stroke in 32 countries (INTERSTROKE): a case-control study. Lancet 2016;388:761-75.

47 Eliassen B-M, Melhus M, Hansen KL, et al. Marginalisation and cardiovascular disease among rural Sami in northern Norway: a population-based cross-sectional study. BMC Public Health 2013;13:522

48 Hansen KL, Sørlie T. Ethnic discrimination and psychological distress: a study of Sami and non-Sami populations in Norway. Transcult Psychiatry 2012;49:26-50.

49 Gulsvik AK, Gulsvik A, Svendsen E, et al. Diagnostic validity of fatal cerebral strokes and coronary deaths in mortality statistics: an autopsy study. Eur J Epidemiol 2011;26:221-8.

50 Pettersen T, Brustad M. Same Sámi? A comparison of self-reported Sámi ethnicity measures in 1970 and 2003 in selected rural areas in northern Norway. Ethn Racial Stud 2015;38:2071-89.

51 Langhammer A, Krokstad S, Romundstad P, et al. The HUNT study: participation is associated with survival and depends on socioeconomic status, diseases and symptoms. BMC Med Res Methodol 2012;12:143. 